\title{
Eyelid discoid lupus erythematosus
}

\section{Mehdi Khallaayoune, Siham Belmourida, Fatima Azzahra Elgaitibi, Mariame Meziane, Nadia Ismaili, Leila Benzekri, Karima Senouci}

Department of Dermatology, Ibn Sina University Hospital, Mohammed V University, Rabat-Morocco

Corresponding author: Mehdi Khallaayoune, MD, E-mail: khallaayounemehdi@gmail.com

Discoid lupus erythematosus (DLE) most commonly affects the face and scalp. Palpebral involvement is rare and not evocative when presenting as the prime manifestation of the disease. We report hereby the case of a young male patient with isolated palpebral and labial DLE.

A 34-year-old patient with no medical history was referred from ophthalmology for an erythematous plaque of the eyelid resisting usual treatment of blepharitis. Skin examination revealed a congestive erythema on the right lower eyelid with eyelash fall (Fig. 1). There was also an atrophic cheilitis of the lower lip with slight erosions (Fig. 2). Scalp, oral mucosa and the rest of the integument were not affected. Skin biopsy of the eyelid revealed marked orthokeratosis with slight basal vacuolization and perivascular lymphoplasma cells infiltrate. Direct immunofluorescence displayed a positive lupus band (Fig. 3). Work-up for systemic involvement was negative. Ophthalmologic assessment found no intraocular involvement. Hydroxychloroquine $200 \mathrm{mg}$ twice a day with clothing and chemical photoprotection were implemented allowing significant improvement after 3 months (Fig. 4).

Palpebral involvement of DLE is uncommon compared to the other suggestive locations including scalp, nose, cheekbones, ears, neckline and hands. An isolated involvement does not suggest DLE at first sight and often leads to delayed diagnosis while scarring and lid deformities might be expected if left untreated [1]. Most commonly it presents as erythematous telangiectasic scaly plaques on the external third of lower eyelid. Blepharitis-like, madarosis, periorbital edema or cellulitis presentations have also been reported [2] Differential diagnosis may arise with several chronic palpebral dermatoses, as carcinomas, eczema,

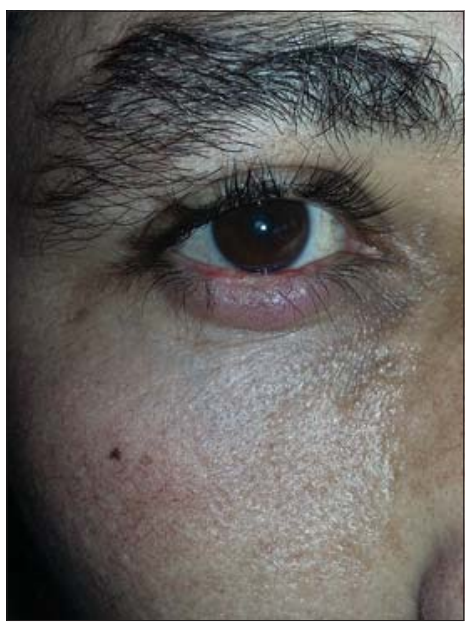

Figure 1: Congestive erythematous lower eyelid with eyelash fall.

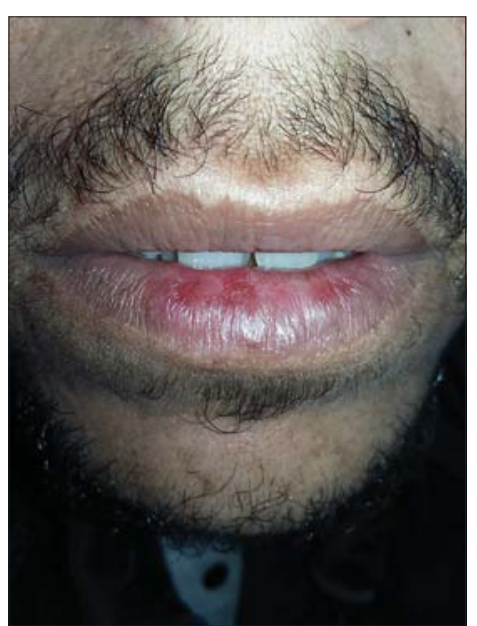

Figure 2: Atrophic cheilitis of the lower lip with slight erosions.

\footnotetext{
How to cite this article: Khallaayoune M, Belmourida S, Elgaitibi FA, Meziane M, Ismaili N, Benzekri L, Senouci K. Eyelid discoid lupus erythematosus. Our Dermatol Online. 2021;12(e):e28

Submission: 27.02.2021; Acceptance: 24.04.2021

DOI:10.7241/ourd.2021e.28
} 

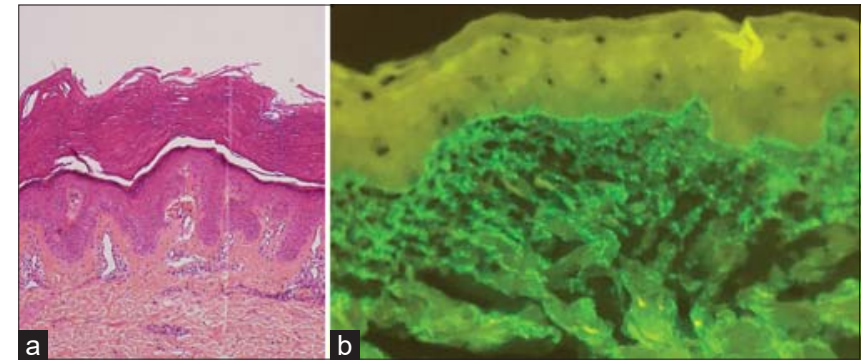

Figure 3: (a) Marked orthokeratosis with slight basal vacuolization and perivascular lymphoplasma cells infiltrate; (b) Positive lupus band on direct immunofluorescence.

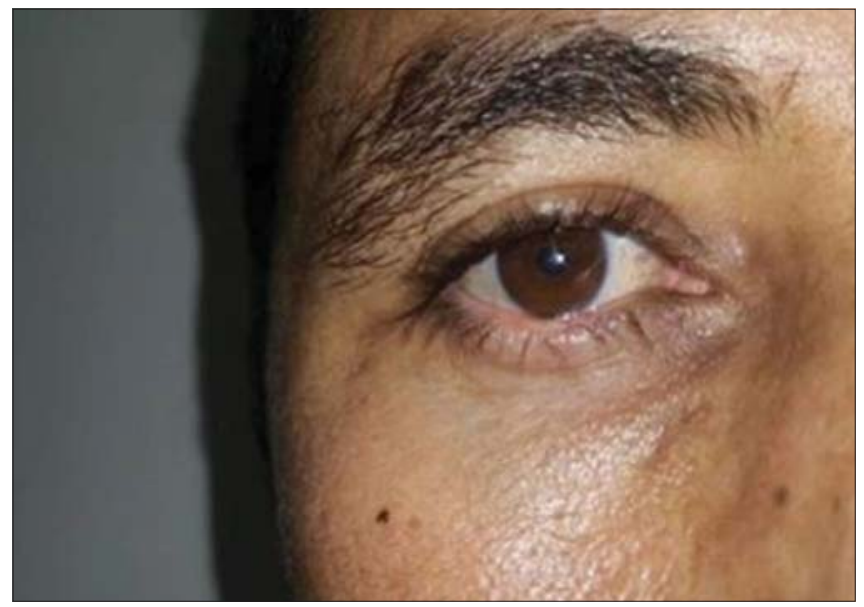

Figure 4: Improvement of erythema with eyelash regrowth after 3 months of hydroxychloroquine.

blepharoconjunctivitis, or seborheic dermatosis. Assessment for intraocular involvement such as keratitis should always be performed [3]. Early recognition and treatment are essential to avoid eyelid complications as ectropion, entropion, and trichiasis. Photoprotection and antimalarials are the mainstay treatment showing remarkable efficacy.

\section{Consent}

The examination of the patient was conducted according to the principles of the Declaration of Helsinki.

The authors certify that they have obtained all appropriate patient consent forms, in which the patients gave their consent for images and other clinical information to be included in the journal. The patients understand that their names and initials will not be published and due effort will be made to conceal their identity, but that anonymity cannot be guaranteed.

\section{REFERENCES}

1. Jisha K, Rajesh PS, Kurien G, Sathish G, Vijayamma N. Chronic blepharitis like picture in patients with Discoid lupus erythematosis - Case series. Nepal J Ophthalmol. 2017;9:175-9.

2. Darjani A, Rafiei R, Mesbah A, Golmohammadi R, Rafiee B, Movaseghi M. Discoid lupus erythematosus presenting as upper eyelid edema and erythema. Acta Med Iran. 2017;55:474-6.

3. Arrico L, Abbouda A, Abicca I, Malagola R. Ocular complications in cutaneous lupus erythematosus: a systematic review with a meta-analysis of reported cases. J Ophthalmol. 2015;2015:254260.

Copyright by Mehdi Khallaayoune, et al. This is an open-access article distributed under the terms of the Creative Commons Attribution License, which permits unrestricted use, distribution, and reproduction in any medium, provided the original author and source are credited. Source of Support: Nil, Conflict of Interest: None declared. 